\title{
The Effect of Physical Condition on the Artistic Gymnastic Basic Skills
}

\author{
Ratna Budiarti \\ Faculty of Sport Sciences \\ Universitas Negeri Yogyakarta \\ Yoyakarta, Indonesia \\ ratna_budiarti@uny.ac.id
}

\begin{abstract}
Physical conditions are considered a very important framework to develop physical techniques. The aim of this study is to determine the effect of physical condition in the development of Artistic Gymnastic Basic Skills. The descriptive qualitative method was applied using the survey method. The sample was defined as 100 students, between 7-9 years old from Sleman. Tests and measurements of biomotor (flexibility and power) and gymnastic basic skills (forward roll and bending) were collected as part of the study. The data analysis techniques used was a linear regression. The results of this study have been shown a significant impact of the physical condition on the basic artistic gymnastics skills.
\end{abstract}

Keywords—artistic gymnastics, talent scouting, basic skills

\section{INTRODUCTION}

Successful young gymnasts are part of a highly select group characterized by specialized motor skills, body size, and shape [1]. This result reflects the interactions between varied environmental conditions and genetic endowments. As a group, they generally demonstrate growth characteristics associated with late-maturing girls. The principal conditions contributing to gymnast's success, in terms of environmental settings, are family support, training condition, continuous engagement in competitions and excellent coaching throughout their career [2]. The anthropometric traits, somatotype, body composition, and biological maturation characteristics have been useful in the prediction success of the gymnastics competition [3]. These elements have been used widely during the initial identification phase and the training process [3].

Different studies have been shown that gymnasts are shorter (in height) than their equals of the same chronological age. They will reach their predicted target adult heights, with the development of appropriate body mass for their maturity status (biological age); but the pubertal maturation is going to be retarded [1]. Additionally, [1] have been suggested that the effects of intensive training in the linear growth of female gymnasts, is almost negligible. But there is controversy around this topic [6].

Studies on elite female gymnasts are not frequent, especially on elite gymnasts in various stages of their national/international careers [4]. Nevertheless, available data typically comprises somatic profiles [5] often in combination with biological maturation $[3,5,6]$, somatotype $[3,5]$ and body composition. There are different studies related to this topic but there is no general consensus about how to report that data or how to construct multivariate profiles. Furthermore, there are always problems related to small sample size and limited representativeness, the inclusion of different age groups, the use of different rating classification systems, the presence of diverse characteristics of training loads, as well as the problem of how to relate all these features with the aim to characterize an elite gymnast. These elements are very important in the identification of elite gymnasts from an early age.

The physique is considered an important component. Actually, it is considered alongside an individual's motor skills. The assessment of motor abilities in gymnasts' populations can be a problem due to the vast array of methodology and expert opinions. The measurements are difficult for the inclusion of complex parameters, such as the wide variety of technical skills, muscular contractions, and speed of stretch. Furthermore, the complexity of gymnastics events (four for females) requires not only different training approaches also require a wide range of physical and physiological testing in order to monitor the progress of each gymnast. Additionally, close monitoring of motor fitness should help gymnasts to avoid injury and enhance performance by maximizing training effects and reducing overtraining. Some tentative test batteries are available, but they usually are local or specific in the identification of a child with a specific motor profile. Moreover, it has been difficult to associate such results with competition marked on different apparatus or total scores $[4,5]$

The learning process of gymnastics skills is complex. It requires a transition from the methodological principles of a suitable level of simple motor skills to complex motor skills. The acquisition of skills isn't in concordance with the current abilities and it could fail. In that matter, each gymnastics skill has a potentiality of vertical and horizontal progression which makes gymnastics one of the most attractive sports nowadays. In this sport, is very important to distinguish a path from natural movement to very complex acrobatic figures. Gymnastics is made of numerous discrete skills which turn to 
complex closed serial skills with the use of extraordinary inventiveness and originality.

The wide range of movements and positions makes it possible for children to develop a quality reserve of sensory and motor pathways and make a positive stimulus on their psychosomatic status. Highly developed motor abilities and large movement skills can conduce to a better daily functioning. During that time, motor learning needs to be perceived as a process of acquisition of gradual skills. This process starts with clumsy and sows attempts, over basic structures acquisition, to the superior performance of skills in different circumstances.

Fundamental movement skills (FMS) enable children to interact and explore their environment. Besides being fundamental and irreplaceable in most human abilities and features, these movement structures make a firm base for the development of more complex movement skills.

Although some FMS, like walking, are learned naturally throughout the developmental process, most of these skills need to be learned and further improved. A child with not proper developed FMS will no have a quality basis simultaneous which further specific movement patterns. Besides, if FMS is not mastered at the young age, the motor activities advancement throughout life can be disrupted.

Gymnastics belongs to a group of basic sports defined as physical activities which contain such educational possibilities that can only partially be mastered with other sports disciplines. Also, the practice of basic sports as part of the educational process of children from an early age develops morphological characteristics for other sports.

Numerous studies that deal with the abilities needed for successful gymnastics skills performance have been published: speed, strength, endurance, agility, flexibility, balance, and explosive strength. However, little research has been identified the selection and influence of FMS for quality basic and complex gymnastics skills acquisition exist. It is important to scientifically justify these relationships nowadays since the International Gymnastics Federation (FIG) throughout their Foundation courses also uses these pedagogical tools. The aim of this study is to determine the effect of physical condition especially flexibility and power on the basics skills of gymnastic (bending and forward roll).

\section{METHODS}

This research has been used as a descriptive quantitative method. The survey was applied to a sample of 100 students, with 7-9 years old from Sleman area. The exclusion criteria applied were: the student from Sleman elementary school, no evidence of health problems or injuries, a school without gymnastics extracurricular activity. The sampling technique was based on a purposive sampling taking into consideration the research objectives. Regression test was applied as part of the data analysis techniques. Several tests need to be done with the aim to identify on early childhood, the presence of basic skills of artistic gymnastics. The examples of basic gymnastic skills tests are forward roll and bending over.

\section{RESULT AND DISCUSSION}

TABLE I. LEVEL OF SELECTED PHYSICAL CONDITION AND BASIC SKILL

\begin{tabular}{|c|c|c|c|c|}
\hline Category & \multicolumn{2}{|c|}{ Physical Condition } & \multicolumn{2}{c|}{ Basic Skill } \\
\cline { 2 - 5 } & Flexibility & Power & Forward roll & Bending \\
\hline Very Good & 0 & 8 & 8 & 2 \\
\hline Good & 9 & 11 & 20 & 30 \\
\hline Quite Good & 22 & 25 & 41 & 35 \\
\hline Less Good & 39 & 21 & 26 & 22 \\
\hline Not Good & 30 & 35 & 5 & 11 \\
\hline
\end{tabular}

From the table above, it can be seen that the result of the selected physical condition and basic skill of gymnastic showed that the flexibility of researh subject generally less good (39\%) and not good (30\%), while quite good flexibility $(22 \%)$ and only $9 \%$ were good flexibility. Power test result showed that majority of research subject included in the category not good power $(35 \%)$, while the less good power $(21 \%)$, quite good (25\%), Good (11\%), and very good (8\%).

In the basic skill test result, forward roll test result showed that majority of research subject inculded in quite good with percentage $41 \%$, while other category showed not good (5\%), less good $(26 \%)$, good $(20 \%)$, and very good $(8 \%)$. Bending test result showed that generally quite good $(35 \%)$, good $(30 \%)$ less good $(22 \%)$, while the very good research subjects were only $2 \%$ of the total students and $11 \%$ were included in the category not good.

TABLE II. LINEAR REGRESSION ANALYSIS RESULT

\begin{tabular}{|l|l|l|}
\hline Category & Sig. & Explanation \\
\hline Bending & & \\
\hline Flexibility & 0,00 & Significant \\
\hline Power & 0,072 & Not Significant \\
\hline Forward Roll & & \\
\hline Flexibility & 0,043 & significant \\
\hline Power & 0,000 & significant \\
\hline
\end{tabular}


From the table above it can be seen that the results of the linier Regresion test showed that only flexibility have significant effect on bending and in forward roll, flexibility and power have significatn effect.

There is need many factor to be include in artistic. Gynastics talent scouting instrument.gymnastics is a type of complex exercise. there are several components or elements needed to do gymnastic movements. each movement has its own biomotor form and needs. so that the influential biomotor will be in accordance with the type of motion carried out. When learning gymnastics skills one has to stick to methodological principles of complex motor skills acquisition after reaching suitable level of simple motor skills [5].

\section{CONCLUSION}

Physical conditions have an important role in achieving good gymnastic performance. Each movement has different biomotor needs. The trainer must train the dominant biomotor used.

\section{REFERENCES}

[1] A. D. G. Baxter-Jones, A. M. Thompson, R. M. Malina Growth and maturation in elite young female athletes. Sports Med Arthrosc Rev. 2002;10:42-49.

[2] J. Côté The influence of the family in the development of talent in sport. Sport Psychol. 1999;13:395-417.

[3] M. Massidda, S. Toselli, P. Brasili, C. M. Calò, "Somatotype of Elite Italian Gymnasts" Coll Antropol. 2013;37:853-857.

[4] J. Pool, R. A. Binkhorst, J. A. Vos, "Some anthropometric and physiological data in relation to performance of top female gymnasts," Int Z Angew Physiol. 1969;27:329-338.

[5] A. L. Claessens, "Talent detection and talent development: kinanthropometric issues," Acta Kinesiol Univ Tartu. 1999;4:47-64.

[6] N. A. Eorgopoulos, A. Theodoropoulou, M. Leglise, A. G. Vagenakis, K. B. Markou, "Growth and skeletal maturation in male and female artistic gymnasts," J Clin Endocrinol Metab. 2004;89:4377-4382.

[7] H. Fink, A. Muscat, K. Russell, "Long term athlete development gymnastics the ultimate human movement experience," Ottawa: Gymnastics Canada Gymnastique; 2008 